\title{
A RESPEITO DA MAIERIALLDADE DO PATRIMÔNIO IMATERIAL: O CASO DO INRC PORONGOS
}

\author{
Cristian Jobi Salaini
}

Escola Superior de Propaganda e Marketing - Brasil

Lucas Graeff

Centro Universitário La Salle - Brasil

Resumo: O colecionamento e a conservação de "bens culturais" vêm ganhando em complexidade pela inclusão de temas oriundos de minorias étnicas e econômicas. Apesar do consenso relativo ao conceito de patrimônio cultural proposto pela Unesco, a definição do que deve ser preservado e celebrado como "bem cultural" pode ser objeto de lutas políticas, jurídicas, econômicas e sociais. Visando refletir sobre as consequências dessas lutas, este artigo aborda o processo de inventário de referências culturais em torno do Massacre de Porongos, evento da Revolução Farroupilha (1835-1845) que vem servindo de apoio à configuração de uma identidade negra e gaúcha no Rio Grande do Sul. Segundo os autores, apesar de se apresentar no registro de "patrimônio imaterial", o processo de inventário possibilitou a fabricação de um "corpo" (de textos e imagens) e a delimitação de "lugares" (de memória) a partir dos quais os referentes culturais ditos "imateriais" vêm se inscrever.

Palavras-chave: cultura material, inventário de referências culturais, Massacre de Porongos, patrimônio cultural.

Abstract: The collection and conservation of "cultural objects" has been gaining in complexity with the inclusion of non-material associations regarding ethnic and economic minorities. Despite the consensus on the concept of cultural heritage proposed by Unesco, the definition of what should be preserved and celebrated as "cultural object" may be subject of political, legal, economic and social struggles. In order to reflect upon the consequences of these struggles, this article discusses the process of inventory of cultural references related to the Porongos Massacre, an event of the Farroupilha's Revolution (1835-1845). These cultural references are serving in the configuration of black people's and gauchos identities. According to the authors, althought relating to the "intangible heritage", the process of inventory has enabled the 
fabrication of a "body" (text and images) and the definition of "places" (from memory) from which the cultural references so-called "non-material" come subscribe.

Keywords: cultural heritage, inventory of cultural references, material culture, Porongos Massacre.

\section{Introdução}

O colecionamento e a conservação de "bens culturais" vêm ganhando em complexidade com a inclusão de temas oriundos de minorias étnicas e econômicas. Da inscrição da capoeira de Angola (Pelegrini, 2008) e dos doces de Pelotas (Rieth et al., 2008) nos Livros de Registro dos Saberes e de Registro das Formas de Expressão do Instituto do Patrimônio Histórico e Artístico Nacional (Iphan), passando pela idealização e patrimonialização de cidades como Porto Nacional (TO) e Goiás (GO) (Delgado, 2005; Peixoto, 2005): a atribuição de "valor cultural" a determinados bens, objetos e processos contribui não apenas para a produção de novos saberes e práticas, mas sobretudo para a multiplicação de pontos de vista sobre o papel do patrimônio na afirmação e redefinição de identidades nacionais, regionais e locais.

Frente a essa diversidade, a noção mesma de "bem cultural" é problematizada por diversos autores. Para José Reginaldo Santos Gonçalves (2002, p. 23), por exemplo, o colecionamento e a patrimonialização de bens culturais responderia a um "enquadramento mítico", onde "os objetos que vêm integrar as coleções ou os patrimônios culturais [...] são recodificados com o propósito de servir como sinais diacríticos das categorias e grupos sociais que venham a representar". Segundo Dominique Poulot (2008, p. 26-27), quando patrimonializados, os bens culturais funcionam como "sinônimo de vínculo social", a tal ponto que "a afirmação de um ponto de vista diverso - a recusa da patrimonialização ou a sua crítica radical - é obrigatoriamente considerada como 'vândala', ou pelo menos insignificante, no debate público". ${ }^{1}$ Ainda de acordo com José Reginaldo Santos Gonçalves (2007, p. 9),

\footnotetext{
1 Sobre o emprego do termo "vandalismo" como sinônimo de depredação e destruição de monumentos históricos e monumentos em geral, ver o capítulo III do livro A alegoria do patrimônio, de Françoise Choay (2001).
} 
seja no contexto de seus usos sociais e econômicos cotidianos, seja em seus usos rituais, seja quando reclassificados como itens de coleções, peças de acervos museológicos ou patrimônios culturais, os objetos materiais existem sempre, necessariamente, como partes integrantes de sistemas classificatórios. Esta condição lhes assegura o poder não só de se tornar visíveis e estabilizar determinadas categorias socioculturais, demarcando fronteiras entre estas, como também o poder, não menos importante, de constituir sensivelmente formas específicas de subjetividade individual e coletiva.

No final das contas, vem cabendo às instituições e organismos nacionais e internacionais a delimitação de um conceito de patrimônio cultural capaz de abarcar as mais diversas noções e definições de bens culturais que devem ser identificados, colecionados, preservados e, se for o caso, tombados. Visto que a preocupação maior desses organismos e instituições é a de dar conta não apenas de monumentos, mas de "conjuntos" e "locais de interesse", a noção de patrimônio cultural acaba servindo para incorporar toda produção humana - desde que considerada em virtude de seu valor excepcional do ponto de vista histórico, estético, artístico e/ou científico, como sublinha a Convenção para a proteção do patrimônio mundial, cultural e natural (Unesco, 1972). ${ }^{2}$

Esses são alguns dos sentidos pelos quais o patrimônio cultural pode ser pensado como uma "categoria de pensamento" (Gonçalves, 2002, 2007): trata-se de um conceito que possibilita às sociedades humanas uma reflexão histórico-identitária sobre si mesmas, de maneira que toda prática patrimonial acaba por se transformar em objeto de lutas políticas, jurídicas, econômicas e sociais. Por um lado, como sublinha bem Marta Anico (2005, p. 72),

nessa conjuntura pautada pela ausência de referentes de identidade, estabilidade e continuidade, em face de uma ameaça de ruptura e de desaparecimento de recursos culturais, real ou imaginada, produz-se um sentimento nostálgico em relação ao passado, abrindo o caminho ao desenvolvimento de uma indústria da

\footnotetext{
2 Segundo a Unesco, o patrimônio cultural abrange os monumentos (obras arquitetônicas), os conjuntos (grupos de construções) e os locais de interesse (obras humanas ou conjugadas entre o Homem e a Natureza). No que diz respeito ao Iphan, foram criados Livros de Registro (dos Saberes, das Celebrações, das Formas de Expressão e dos Lugares), onde estão sendo inscritos "os conhecimentos, modos de fazer, rituais, festas, manifestações literárias, musicais, plásticas, cênicas e lúdicas, mercados, feiras, santuários, praças e demais espaços, tendo como referência 'a continuidade histórica do bem e sua relevância nacional para a memória, a identidade e a formação da sociedade brasileira'.” (Meira, 2004).
}

Horizontes Antropológicos, Porto Alegre, ano 17, n. 36, p. 171-195, jul./dez. 2011 
nostalgia em que o passado é resgatado, idealizado, romantizado e não raras vezes inventado, mediante processos que incluem a patrimonialização da cultura.

Por outro lado, tomando em consideração os casos da Villa Mimosa, em Canoas (RS) (Oliveira; Graeff, 2011), e o do Parque da Água Branca, em São Paulo (Sagi, 2008), fica claro que a definição e a celebração de determinados temas e objetos enquanto "bens culturais" resulta muitas vezes de verdadeiras "batalhas no campo da memória" (Ferreira, 2008).

Visando contribuir para a reflexão a respeito das consequências dessas lutas no campo da memória e do patrimônio, este artigo aborda o processo de execução de um Inventário Nacional de Referências Culturais (INRC) realizado pelo Iphan e por uma equipe de trabalho interdisciplinar da Universidade Federal do Rio Grande do Sul (UFRGS) coordenada pela antropóloga Dra. Daisy Barcellos. A preocupação fundamental do inventário foi a de definir a pertinência de determinadas localidades, práticas sociais e produções culturais relacionadas ao Massacre de Porongos enquanto referentes culturais a serem inscritos nos Livros de Registro do Iphan. Ao mesmo tempo, procurouse compreender como e por que o Massacre de Porongos se inscreve num contexto amplo de discussões que problematizam o lugar e a participação do negro dentro da sociedade brasileira e rio-grandense, desembocando na formulação e reformulação de identidades locais por grupos e atores de forma ampla pelo estado. ${ }^{3}$

Neste artigo, nos propomos a aprofundar esses dois polos de discussão relativos ao Massacre de Porongos a partir da imbricação dos referentes culturais ditos "materiais" e "imateriais" recuperados, documentados e produzidos durante o processo de inventário. Nós procuraremos mostrar como o INRC se impõe como ponto de partida (e, por que não dizer, de chegada) para o mapeamento das localidades, práticas sociais e produções culturais que, independentemente de serem consideradas ou não "patrimônio nacional", irão servir de apoio ao desenvolvimento e à consolidação de uma identidade negra e gaúcha no Rio Grande do Sul. Em outras palavras, defendemos a tese de que o processo de inventário de referentes culturais, ao elaborar documentos e identificar práticas sociais e "lugares de memória" (Nora, 1993), contribui

3 Como veremos adiante, o contexto de memoralização dos lanceiros negros envolve muitos grupos do estado que não estavam envolvidos nas discussões iniciais em torno da construção de tal memorial. 
para a materialização de bens culturais ditos "intangíveis" ou "imateriais", que passarão a integrar a "teia de objetos" (Gonçalves, 2002, 2007) cujo peso de verdade é frequentemente evocado nas lutas de definição de identidades locais. Nossa formação de antropólogos nos leva a rejeitar, de um ponto de vista epistemológico e ontológico, a distinção entre bens materiais e imateriais, assim como a dicotomia entre razão prática e razão simbólica (cf. Cassirer, 1994; Geertz, 1989; Sahlins, 2003). Nós trabalhamos com a premissa de que os seres humanos se relacionam com o mundo a partir de esquemas e sistemas simbólicos, de maneira que toda distinção entre tangível e intangível, natural e cultural e essencial e acidental costuma nos informar mais sobre o grupo social que pensa e organiza o seu mundo a partir dessas dicotomias do que sobre categorias de entendimento ou classificatórias supostamente universais. ${ }^{4}$

A discussão será apresentada em três momentos. A fim de situar o leitor a respeito das condições de produção do INRC Porongos, nós abordaremos o processo de inventário, começando pela apresentação do Massacre de Porongos e das querelas sociais e historiográficas em torno desse evento derradeiro da Revolução Farroupilha (1835-1845), passando pelas localidades visitadas durante a pesquisa e apresentando alguns "marcos memoriais", evocados pelas pessoas entrevistadas, que são relevantes para a discussão que propomos aqui. Em seguida, entraremos numa reflexão a respeito da "etnização" dos lanceiros negros, figuras emblemáticas do massacre, cuja participação trágica no conflito contribui para sublinhar os limites da luta de valores e de pontos de vista a respeito do papel do negro na formação do estado do Rio Grande do Sul. Por fim, elaboraremos a tese da inscrição material dos referentes culturais documentados e elaborados a partir do processo de inventário. Nesse sentido, apesar de se apresentar no registro de "patrimônio imaterial", o INRC acaba agindo na fabricação de um "corpo" (de textos e imagens) e na delimitação de "lugares" (de memória) a partir dos quais os grupos e atores ligados ao movimento negro se inscrevem e se referenciam.

4 A respeito das discussões em torno da materialidade e da imaterialidade dos bens culturais, ver os trabalhos de Gonçalves (2005, 2007) e Poulot (2008), por exemplo. 


\section{Os lanceiros negros e a Revolução farroupilha: marcos memoriais de um "patrimônio imaterial"}

O processo de inventariamento dos referentes culturais relacionados ao Massacre de Porongos tem sua origem em disputas histórico-identitárias entre diferentes atores e grupos interessados em postular as características fundamentais do gaúcho e, por extensão, daquilo que caracterizaria o estado do Rio Grande do Sul de um ponto de vista folclórico e cultural. Quando se trata de definir o "homem rio-grandense" ou o "gaúcho típico", a polêmica costuma focar determinados eventos históricos - a Revolução Farroupilha, em especial - e a herança sociocultural deixada ao longo dos diversos fluxos migratórios que colonizaram o estado. ${ }^{5}$

No que diz respeito ao Massacre de Porongos, é a participação do negro na construção do gaúcho e do estado que está em questão. Apesar de pouco presentes na historiografia tradicional, os negros tiveram participação fundamental durante a Revolução Farroupilha. Segundo Raul Carrion (2008), negros livres e escravos lutando sob a promessa de libertação teriam somado de um terço à metade do exército rebelde republicano. Distribuídos entre a cavalaria e a infantaria - divisões criadas, respectivamente, em 12 de setembro de 1836 e 31 de agosto de 1838 -, eles passaram a ser denominados "corpos de lanceiros negros" e viriam a participar de momentos fundamentais da disputa entre imperiais e republicanos durante a revolução. ${ }^{6}$

O Massacre de Porongos - conhecido também como "Surpresa", "Batalha", ou "Traição" de Porongos - ocorreu às vésperas da assinatura do Tratado de Ponche Verde, que selaria a paz entre republicanos e imperiais e encerraria a Revolução Farroupilha após 10 anos de conflito. Mais precisamente, no dia 14 de novembro de 1844, um dos corpos de lanceiros negros liderados pelo general David Canabarro se encontrava próximo ao Cerro de

\footnotetext{
Anualmente comemorada durante a Semana Farroupilha, a revolução é um episódio constantemente trabalhado pela memória local e responsável pela construção da identidade gaúcha (cf. Pesavento, 2005).

6 Segundo Spencer Leitman (1997), os negros já haviam desempenhado papel fundamental antes mesmo da criação desses corpos, como na tomada de Porto Alegre, em setembro de 1835, e a de Pelotas, ocorrida em abril de 1836. Negros, na condição de libertos e alforriados, assim como na de fugidos do Uruguai, contribuíram na causa farroupilha não apenas como soldados. Foram tropeiros, mensageiros, campeiros e fabricadores de pólvora.
}

Horizontes Antropológicos, Porto Alegre, ano 17, n. 36, p. 171-195, jul./dez. 2011 
Porongos, então município de Piratini e atualmente pertencente à cidade de Pinheiro Machado. Durante a madrugada, os homens que compunham essa divisão do exército farroupilha foram atacados e mortos por uma tropa imperial liderada pelo coronel Francisco Pedro de Abreu, o Moringue.

Apesar de documentos da época indicarem que o corpo de lanceiros negros estacionado próximo ao Cerro de Porongos estava desarmado (Carrion, 2008; Leitman, 1997), há um ponto polêmico entre historiadores - e, atualmente, entre os grupos que disputam a memória do acontecimento: a eventualidade de o general Canabarro haver desarmando e separado os lanceiros negros da tropa momentos antes do ataque imperial. Ora, essa polêmica relacionada ao papel de David Canabarro é fundamental para pensar os desdobramentos políticos, históricos e sociais em torno do Massacre de Porongos. Afinal de contas, Canabarro não é apenas uma figura fundamental da história do Rio Grande do Sul; ele pode ser considerado como patrono ou herói maior do movimento tradicionalista. ${ }^{7}$ Nesse sentido, atribuir o papel de traidor ao líder farroupilha implicaria problematizar as origens mesmas do movimento, em maculá-lo do ponto de vista do seu "enquadramento mítico", segundo a expressão de José Reginaldo Santos Gonçalves (2002).

A peça fundamental que sustenta a polêmica em torno da figura de Canabarro ao final da Revolução Farroupilha é uma correspondência entre o então barão de Caxias e o coronel Francisco Pedro de Abreu. A "Carta de Porongos", como ficou conhecida, traria evidências de um acordo prévio entre Caxias (comandante do exército imperial no conflito) e David Canabarro. Dentro das negociações de paz, o Império do Brasil mostrava-se contrário à promessa de libertação dos escravos que lutavam ao lado dos rebeldes. Assim, Canabarro precisaria "trair" seus lanceiros negros a fim de garantir o Tratado de Ponche Verde. Por outro lado, ainda que a carta exista, existe a possibilidade dela ter sido forjada pelos imperiais com a intenção de desmoralizar o general Canabarro, um dos ícones da revolução.

A partir dos estudos de Daniela Carvalho e Vinícius Oliveira (2008), é possível identificar três momentos onde a polêmica sobre a carta e o Massacre

\footnotetext{
Em 1947, quando da criação do departamento de tradições no grêmio da escola Colégio Júlio de Castilhos, em Porto Alegre, ato inaugural do movimento tradicionalista, uma das primeiras ações foi receber as cinzas de David Canabarro trazidas pela Liga da Defesa Nacional. Esse fato está na base da criação do “35 CTG”, primeiro centro de tradições gaúchas do estado (Maciel, 1994a).
} 
de Porongos emerge entre os historiadores. O primeiro ocorreu no final do século XIX entre os historiadores Alfredo Varela e Alfredo Ferreira Rodrigues. Para Varela, houve a traição de David Canabarro em Porongos, pois o general estaria ciente da proximidade das tropas imperiais, mas não teria tomado as devidas providências para salvar seus combatentes. Já Ferreira Rodrigues defende a tese da carta forjada. O segundo momento de reflexão historiográfica ocorreu nas décadas de 1920 e 1930 através de autores como Dante de Laytano, Othelo Rosa, Walter Spalding e João Maia. O eixo central das discussões nesse período não versa sobre a possibilidade de "traição" ou "surpresa", mesmo que a tendência seja para o segundo termo. Ao mesmo tempo, vale destacar o papel de Dante de Laytano na promoção do papel do negro enquanto etnia no Rio Grande do Sul - ainda esse papel seja interpretado através de uma suposta "democracia racial dos pampas". Por fim, é ainda nas décadas de 1920 e 1930 que surgem os primeiros CTGs (centros de tradições gaúchas) e que se difunde a ideia de que a escravidão no Rio Grande do Sul teria sido mais branda do que no resto do país.

O terceiro e último momento da polêmica se dá ao longo das décadas de 1970 e 1980. Aqui, encontram-se autores como Moacyr Flores (1985), Spencer Leitman (1987) e Margareth Bakos (1985), que argumentam no sentido de uma traição em Porongos. Conforme salientam Daniela Carvalho e Vinícius Oliveira (2008), os historiadores desse período estão, de forma geral, preocupados em discutir o caráter abolicionista dos rebeldes na Revolução Farroupilha. É fundamental notar que é também nesse último período que surgem as primeiras apropriações do movimento negro em relação ao tema, através do poeta e escritor Oliveira Ferreira Silveira e do historiador Guarani Santos. Ambos são tomados frequentemente como referência ao tema pelos grupos locais responsáveis pela emergência de memória na atualidade.

Diante da indefinição do valor documental da Carta de Porongos e com a certeza de que o corpo de lanceiros negros se encontrava desarmado no momento do ataque dos imperiais, optamos por falar em Massacre de Porongos durante o processo de inventariamento, deixando os termos "traição", "surpresa" ou "batalha" para o uso dos grupos e atores pesquisados conforme suas convicções. Nosso objetivo não foi o de evitar a polêmica, mas o de dialogar com todos os interessados pelo evento e pelo INRC. Assim, delimitamos gradativamente locais e grupos a visitar e a mapear durante o inventário. Entre eles, Movimento Negro Unificado de Porto Alegre, Movimento Negro 
de Guaíba (Centro Cultural Cândido Velho), Movimento Negro de Pinheiro Machado, Grupo Cultural Raízes da África (Porto Alegre), além de moradores do Cerro de Porongos (local onde supostamente ocorreu o massacre), representantes do Movimento Tradicionalista (Zeno Dias, por exemplo) e escritores e políticos interessados pela temática da revolução farroupilha (Alcy Cheuiche e Raul Carrion).

Encontramos diversas narrativas, produções e práticas culturais relativas ao massacre junto a essas diferentes localidades e atores. Rapidamente, identificamos a figura do lanceiro negro como um ponto de apoio imaginário ${ }^{8}$ tanto para a articulação de marcos memoriais quanto para a reformulação e a afirmação de referentes identitários dos diferentes grupos envolvidos. Nesse sentido, a polêmica em torno do Massacre de Porongos se impõe mais como um cenário onde o "verdadeiro caráter" dos combatentes farroupilhas se revela, sejam eles líderes brancos ou lanceiros negros, do que como uma questão eminentemente histórica.

A importância do apoio imaginário fornecido pela figura do lanceiro negro nos foi demonstrada em diversas situações de pesquisa. Durante a Semana Farroupilha de 2005, por exemplo, tivemos a oportunidade de visitar três piquetes cujas atividades estariam relacionadas a algum tema "negro" ou, mais especificamente, ao Massacre de Porongos: o Piquete Mocambo, o Piquete Floresta Aurora e o Piquete Inapiários. No caso do Mocambo, ONG portoalegrense cuja finalidade é a de elaborar projetos relacionados à comunidade carente de Porto Alegre, os lanceiros negros foram apresentados como "verdadeiros escravos", segundo as palavras de Maria Elaine Rodrigues, uma das responsáveis pelo piquete. Para fortalecer essa ideia, foram utilizadas "roupas de escravos" na representação dos lanceiros, que deveriam simbolizar a luta pela emancipação do negro no estado:

8 Pensando a partir dos trabalhos de Bronislaw Baczko (1985), o imaginário social tem o papel de nortear simbolicamente o trabalho da memória, atuando na produção e reprodução dos elementos que podem constituir meios de legitimação e eficácia a um empreendimento de reconstituição identitária. Segundo o autor, que se contrapõe às páginas em que Marx analisa a Revolução Francesa a partir da noção de ideologia, deve-se pensar o imaginário não como "máscaras" cobrindo a "realidade", mas como "“fatos', de signos e imagens, de gestos e figuras" que tornam possíveis aos homens de "se comunicarem entre si e de se reconhecerem ao longo do caminho" (Baczko, 1985, p. 321). Em outras palavras, os projetos, sonhos e esperanças coletivas cristalizam-se em linguagens e modos de expressão que, apesar de imaginários, contribuem para a articulação de marcos e lugares de memória reconhecidos e legitimados socialmente. A esse respeito, ver também Durand (2003) e Silva (2001).

Horizontes Antropológicos, Porto Alegre, ano 17, n. 36, p. 171-195, jul./dez. 2011 
Quando tu falas em lanceiros negros tu nos coloca uma coisa muito forte que mexe conosco. O nosso lema aqui dentro desse acampamento farroupilha é bem assim: em memória dos lanceiros - grife-se estes lanceiros, então... em memória dos lanceiros, lutem, negros! Grifem-se também negros... então porque... porque na memória deles que deram a vida, que foram emboscados, né, que foi uma luta tão inglória mas que estiveram presentes, o que nós temos que fazer... continuar a luta! Então é essa a proposta do mocambo: lutem, negros! Mas com aquilo que estiver ao seu alcance. Se o nosso alcance nesse momento é minimamente organizado, e estar também participando, então esse espaço também é nosso, porque nós também amamos este Rio Grande. E além do amor construímos de alguma forma esse grande sentimento e honradez que há neste estado. (Maria Elaine Rodrigues, entrevista em 17 de setembro de 2005).

No caso do Piquete Floresta Aurora, além alguns objetos fazendo alusão ao Massacre de Porongos, ${ }^{9}$ participamos de algumas palestras relacionadas aos lanceiros negros e de atividades diversas relacionadas às tradições gaúchas, como a execução e preparo de danças e comidas típicas. Porém, um dos aspectos interessantes da visita ao piquete foi o encontro com Nílton Marques da Rosa, patrão do Floresta Aurora e também participante da cavalgada da Semana da Consciência Negra organizada pelo grupo Lanceiros Negros Contemporâneos. ${ }^{10}$ Segundo Nílton, apesar de ser fundamental "trazer a história dos lanceiros para as pessoas", é preciso evitar a polêmica em torno do Massacre de Porongos:

Porque nós jamais podemos estar condenando alguém, dizendo "olha, nós fomos jogados na fogueira, fomos jogados na bucha do canhão"... nós estamos numa guerra! E numa guerra estamos sujeitos a tudo... o branco, o preto, o pardo... qualquer um! É uma guerra! Numa guerra não se escolhe raça, nem cor,

9 Destacamos a presença de cópias do jornal Como é, que contém a matéria "Nós, os Gaúchos", veiculado pelo Centro Ecumênico da Cultura Negra (Cecune) no mesmo mês do ano de 2004, assim como o material produzido por Raul Carrion (2008) intitulado Os lanceiros negros na Revolução Farroupilha.

${ }^{10}$ Os cavaleiros que formam o corpo de Lanceiros Negros Contemporâneos é constituído, fundamentalmente, por integrantes do Floresta Aurora, algo que faz com que a imagem do piquete seja veiculada ao tema dos lanceiros em diversos eventos (Semana da Consciência Negra e Semana Farroupilha, principalmente). Durante a semana que acolhe o dia 20 de novembro (dia da consciência negra), os Lanceiros Negros Contemporâneos partem do parque Farroupilha, em Porto Alegre, e cumprem um itinerário de lugares de memória relacionados à presença do negro na capital (Largo da Forca, Igreja das Dores, Mercado Público, Igreja Nossa Senhora do Rosário, Praça Carlos Santos, etc.).

Horizontes Antropológicos, Porto Alegre, ano 17, n. 36, p. 171-195, jul./dez. 2011 
nem religião... cada um tem seu propósito. (Nílton Marques da Rosa, entrevista em 17 de setembro de 2005).

O terceiro piquete que contou com atividades relacionadas ao tema dos lanceiros negros foi o dos Inapiários. Durante a sua semana de atividades, o local contou com a presença de Raul Carrion (2008), então vereador de Porto Alegre que acabara de lançar o livro Os lanceiros negros na Revolução Farroupilha, onde é defendida a tese da traição do corpo de lanceiros. Outra presença notável foi a do ator Sirmar Antunes, que veio palestrar sobre o filme Netto perde sua alma,$^{11}$ no qual encarnou um lanceiro negro durante a revolução. Além de palestrantes, o piquete contava com diversas referências escritas e visuais alusivas aos lanceiros, como alguns desenhos inspirados no personagem de Sirmar Antunes.

Em outra oportunidade, durante uma viagem à Caçapava do Sul (RS), tivemos contato com algumas pessoas apontadas pela comunidade local como conhecedoras da história do negro e, mais especificamente, do Massacre de Porongos. Em companhia de Zeno Dias, autodidata e uma das importantes referências do movimento tradicionalista local, visitamos o Vale dos Lanceiros, região situada no interior de Caçapava cujo nome costuma ser atribuído ao corpo de lanceiros negros. Através de Zeno, também entramos em contato com o escritor Alcy Cheuiche (1985), autor de A Guerra dos Farrapos, romance histórico que se passa durante a Revolução Farroupilha.

Ao contrário dos membros dos piquetes negros entrevistados durante a Semana Farroupilha, Alcy Cheuiche e Zeno Dias defenderam a tese da surpresa. Segundo o primeiro, "foi uma guerra, mas não para matar escravos [...]. Caxias não era sanguinário, era pacificador... acusar Canabarro, eu não vejo como". Por sua vez, Zeno diz:

Eu poderia ajudar a incriminar Canabarro, pois minha família era imperial [...] Duque de Caxias pediu para que acabassem as hostilidades. Quem morreu ali?

11 Em 14 de setembro de 2001 foi lançado o filme Netto perde sua alma, dirigido por Beto Souza e Tabajara Ruas, baseado no romance homônimo deste último. A produção cinematográfica, exibida nos cinemas durante a semana das comemorações da Revolução Farroupilha no estado, dá maior visibilidade e fomenta a polêmica entre círculos mais amplos da sociedade. A respeito da discussão que envolve a relação entre a mídia e o "caso Porongos", ver Salaini e Comin (2010). 
Nem todos eram negros. Houve traição sim, mas Canabarro também foi traído. Evidentemente eu estou acusando Chico Pedro. Nunca apareceu tal carta... a carta é forjada, não existiu, foi forjada por Chico Pedro. [...] Se o Canabarro quisesse trair... porque libertou os escravos antes... a escravidão interessava aos imperiais. (Zeno Dias, entrevista concedida em 18 de outubro de 2005).

Zeno ainda fez referência ao apoio dado ao grupo Lanceiros Negros da cidade de Caçapava do Sul para a cavalgada que levou a "chama crioula" até o Cerro de Porongos:

Nós fizemos o movimento da região, dos doze municípios e decidimos, vamos dar uma oportunidade pros Lanceiros Negros prestarem sua homenagem, os Lanceiros Negros em combate [...] a iniciativa foi deles, eles que deram a idéia, eu só copiei, então eles que vão... não importa que sejam poucos, e eu vou acompanhar de carro e é uma aldeia, todos os acampamentos foram em cima do ponto histórico [Cerro de Porongos]. E nós viajamos até um pouco a mais pra ficar em cima do ponto, do ponto histórico, e serve como aprendizado, especialmente pros jovens que nos acompanharam. (Zeno Dias, entrevista concedida em 18 de outubro de 2005).

Junto com a minissérie $A$ casa das sete mulheres, exibida pela Rede Globo de Televisão em 2003, a cavalgada em questão está diretamente relacionada à retomada das discussões sobre a "verdade histórica" do massacre. Desde então, diversos eventos comemorativos vêm fazendo alusão aos lanceiros negros, como as celebrações que ocorrem sempre em novembro, na cidade de Pinheiro Machado e no próprio Cerro de Porongos. Prevê-se ainda a construção de um memorial (Cerro de Porongos/Pinheiro Machado) e de um monumento (Parque Farroupilha/Porto Alegre) através de uma articulação realizada entre os representantes dos movimentos negros locais, a Secretaria de Cultura do Estado do Rio Grande do Sul e Fundação Palmares (ligada ao Ministério da Cultura).

Como se pode perceber, o inventariamento dos referentes culturais em torno do Cerro de Porongos não encerra um campo de interesses exclusivamente ligado aos grupos e atores vinculados ao movimento negro. A partir da pesquisa de campo e de seu peso institucional, o INRC Porongos diz respeito também ao movimento tradicionalista e, mais geralmente, à figura do gaúcho e às práticas culturais e identitárias do estado do Rio Grande do Sul. 
É nesse contexto de polêmicas historiográficas, lugares de memória, marcos imaginários, atores e práticas culturais que o INRC Porongos se inscreve. Mais importante ainda: através da pesquisa de campo, o processo de inventariamento contribui à evocação de elementos memoriais e imaginários relacionados ao massacre, aos lanceiros negros e, por extensão, às possibilidades de revisão do papel do negro na sociedade rio-grandense. Nesse sentido, como iremos argumentar a seguir, o inventariamento de referentes culturais acaba agindo politicamente na reconstituição dos elementos culturais que servem de apoio à formulação e à delimitação de identidades locais e regionais.

\section{0 gauchismo, a etnização dos lanceiros e a politização da cultura}

Ao longo do INRC, uma das preocupações da equipe era a de compreender como o Massacre de Porongos passou a tomar parte de processos de emergência identitária, principalmente na configuração que tomam no Rio Grande do Sul, estado brasileiro reconhecido por suas práticas sociais relacionadas às modalidades existentes no domínio do tradicionalismo e do gauchismo (Maciel, 1994a, 1999; Oliven, 1990, 1992). A figura emblemática do gaúcho, representada pelo homem da campanha, tem na Revolução Farroupilha o cenário para as suas façanhas e heroísmos. Dito de outra maneira, a referência aos heróis farroupilhas se insere na lógica de construção de um "tipo social" a ser cultuado (Brum, 2004). Ao mesmo tempo, é em torno desse episódio que se estabelece simbolicamente a relação do gaúcho com o restante do país, seja para afirmar o seu caráter autônomo, seja para evidenciar que o mesmo é brasileiro por opção (Oliven, 1990).

No Rio Grande do Sul, os atores "oficiais" que trabalham em torno da perpetuação da tradição gaúcha são os tradicionalistas (Oliven, 1992). Eles se constituem em um movimento organizado e atento a tudo que diz respeito aos bens simbólicos do estado, sobre os quais procuram exercer seu controle e orientação. Possuem intelectuais que produzem escritos e que ocupam posições importantes em lugares estratégicos da sociedade gaúcha. Para eles é de fundamental importância demarcar quais são os "verdadeiros" valores gaúchos. Em decorrência disso se colocam como guardiões dessa tradição.

Se, por um lado, os tradicionalistas "constroem" a figura emblemática do gaúcho, por outro, eles contribuem para consolidar as representações identitárias adotadas pelo poder público (Maciel, 1999). Através da formulação de 
leis e instituições inspiradas pelos feitos farroupilhas, o gauchismo se impõe como discurso oficial sobre a identidade do estado do Rio Grande do Sul: em 1954, o governo do estado cria o Instituto de Tradições e Folclore, vinculado à Secretaria de Educação e Cultura; 20 anos depois o instituto transforma-se em Fundação Instituto Gaúcho de Tradição e Folclore; em 1964, uma lei estadual oficializa a Semana Farroupilha e, desde então, a chama crioula passa a ser recebida com todas as honras no Palácio Piratini, sede do governo estadual; em 1966, o hino farroupilha é elevado à condição de hino do estado; em 1980, a erva-mate ${ }^{12}$ torna-se a árvore-símbolo do Rio Grande do Sul; em 1989 as pilchas (conjunto de vestes típicas atribuídas aos antigos gaúchos compreendendo a bombacha, botas, lenço e chapéu) se tornaram traje de honra e uso preferencial; em 1996, um projeto de lei propõe o chimarrão como bebida-símbolo do Rio Grande do Sul; em 2003, um outro projeto prevê o churrasco como prato típico.

Os poderes públicos adotaram, pois, as representações do gaúcho geradas pelo tradicionalismo, tornando-as oficiais. ${ }^{13}$ No entanto o gauchismo, enquanto tradição regional, não se limita ao movimento tradicionalista, mas engloba também os seus opositores, os nativistas. Maciel (1999) demonstra que a palavra "gaúcho", após um processo de ressemantização, passou a se referir a todos os que nascem no estado. Dessa forma o gaúcho é o homem da estância ligado às atividades pastoris de ontem e de hoje e a figura emblemática construída a partir do homem do campo e que se aplica a todos os naturais do estado. Nesse sentido ele se constitui enquanto um tipo social, um modelo, um estereótipo de um grupo social, mas também uma referência identitária que serve para afirmar diferenças, estabelecer distinções entre grupos e para o reconhecimento do grupo enquanto tal.

12 Sob a denominação científica de Ilex paraguariensis, a erva-mate é utilizada no preparo do chimarrão, bebida quente servida numa cuia de porongo e sorvida por intermédio de uma bomba de metal. O hábito de tomar chimarrão é considerado como algo tipicamente gaúcho, embora existam variações dessa prática em países que fazem fronteira com o Rio Grande do Sul.

13 Maciel (1999) mostra que o gaúcho existiu e existe no Uruguai, na Argentina e no sul do Brasil, fruto de um mesmo processo histórico (gado-guerra), mas assume papel e importância histórica diferente em cada país, ou seja, possui um significado distinto em cada local. No caso do Rio Grande do Sul existe uma necessidade de afirmação enquanto gaúcho, diferente dos habitantes de outros estados brasileiros, e enquanto brasileiro, diferente dos gaúchos platinos. Em relação ao movimento tradicionalista a autora destaca que consiste num fenômeno regional em sua origem, hoje difuso em outros estados em virtude das levas de colonizadores rio-grandenses que se dirigiram a essas regiões. Ele implica uma recriação de um determinado modo de vida associado aos gaúchos - vida nas estâncias e no passado, um espaço, um tempo idealizado segundo o imaginário local e recriado segundo critérios contemporâneos. Nesse sentido a cultura tradicionalista se configura a partir da construção e afirmação da identidade gaúcha.

Horizontes Antropológicos, Porto Alegre, ano 17, n. 36, p. 171-195, jul./dez. 2011 
Ao mesmo tempo, as representações do gaúcho não dão conta da expressão identitária de determinados grupos sociais, em especial as de grupos negros, indígenas e de descendentes de colonos alemães e italianos:

Trata-se de uma construção de identidade que exclui mais que inclui, deixando fora a metade do território sul-rio-grandense e grande parte de seus grupos sociais. Apesar do enfraquecimento da região sul do estado, da notável projeção econômica e política dos descendentes dos colonos de origem alemã e italiana que desenvolveram a região norte, da urbanização e da industrialização, o tipo representativo do Rio Grande do Sul continua a ser a figura do gaúcho da Campanha como teria existido no passado. Se a construção dessa identidade tende a exaltar a figura do gaúcho em detrimento dos descendentes dos colonos alemães e italianos, ela o faz de modo mais excludente ainda em relação ao negro e ao índio que comparecem no nível das representações de uma forma extremamente pálida. (Oliven, 1992, p. 100).

No caso do INRC Porongos, é a presença secundária da figura do negro em alguns discursos "oficiais" (tradicionalista e nativista, por exemplo) que se impõe como problema. Por um lado, os grupos pesquisados referiam-se a uma espécie de "silêncio historiográfico" relacionado ao papel do negro na Revolução Farroupilha. Assim, o INRC deveria responder a uma demanda de reivindicação contestatória em relação à historiografia. Por outro lado, o mesmo silêncio poderia ganhar um tom acusatório, servindo de prova das injustiças históricas a serem corrigidas no presente.

Em outras palavras, o cenário político montado em função dos 160 anos do Massacre de Porongos dialoga diretamente com os discursos tradicionalista e nativista, seja para contrapô-los e denunciá-los enquanto discursos hegemônicos e excludentes, seja para se acoplar a eles com a finalidade de reinventar a tradição e fazer do negro, sempre inscrito dentro de uma matriz africana, um dos protagonistas da história do Rio Grande do Sul. Nesse segundo caso, as metáforas utilizadas pelo ator Sirmar Antunes durante celebração do dia 13 de novembro de 2004 são exemplares. Segundo Antunes, seria o momento de o Rio Grande do Sul presenciar um "batuque com churrasco", um "Ogum comendo churrasco" e um "batuque de bombacha". ${ }^{14}$

${ }^{14}$ Sirmar Antunes ficou bastante conhecido por seu trabalho em Netto perde sua alma, onde interpretou o sargento Caldeira. Essa apresentação ocorreu no dia 13 de novembro de 2004 na cidade de Pinheiro Machado e contou com diversas figuras políticas desse município e do estado, assim como diversos representantes da comunidade negra do estado e do país.

Horizontes Antropológicos, Porto Alegre, ano 17, n. 36, p. 171-195, jul./dez. 2011 
Num contexto onde as definições étnico-identitárias do negro costumam passar pelas imagens do carnaval, do futebol, da beleza feminina e da arte primitiva (Barcellos, 1996; Salaini, 2008), as formas de congregação do "ser negro gaúcho" acabam vinculando uma suposta origem africana ou afro-brasileira a elementos da retórica farroupilha. A solução para a problemática da exclusão do negro do discurso tradicionalista e, sob alguns aspectos, da historiografia oficial, passa portanto menos pela ruptura com discursos hegemônicos que por tentativas de readequação e de incorporação de símbolos e imagens celebradas.

De fato, trata-se de uma trama de lutas simbólicas onde a afirmação de uma representação legítima do negro - e, por extensão, do gaúcho - apoiase numa lógica de remanejamentos sucessivos dos discursos hegemônicos. Dito de outra maneira, a tradição que envolve o papel do negro e do gaúcho na formação do estado do Rio Grande do Sul é objeto de disputas políticas silenciosas, cuja manifestação se dá principalmente nos locais de celebração e de reunião dos grupos diretamente envolvidos na querela. Por outro lado, as batalhas travadas no campo da memória e da historiografia contribuem para a formulação de argumentos considerados sólidos, "científicos", a partir dos quais as tentativas de remanejamento podem se afirmar.

É nesse sentido que falamos em "politização da cultura" no caso do INRC Porongos. Na medida em que o Massacre de Porongos é reconhecido como tal - e não como uma "surpresa" ocorrida numa batalha como outra qualquer -, a referência ao evento passa a se articular com outras demandas étnicas, sociais, culturais e patrimoniais, tanto no estado e como no país. ${ }^{15}$ As lutas pela representação legítima de eventos históricos e de locais de celebração e de memória cumprem um papel fundamental no substrato simbólico definidor de grupos e dos discursos hegemônicos e contra-hegemônicos; um substrato simbólico que, na medida em que é evocado e materializado através do processo de inventariamento e patrimonialização, contribui para consolidar, no plano das relações e das práticas identitárias, a situação do negro no Rio Grande do Sul e no Brasil.

\footnotetext{
15 O "lanceiro negro" é um signo acionado e atualizado em situações diversas que, inclusive, extrapolam o contexto inicial que lhe deu origem. O senador Paulo Paim criou, durante o ano de 2004, o troféu e diploma "Lanceiros Negros". De uma forma geral, este visa premiar personalidades, entidades públicas e privadas que apresentam contribuições a campos que apresentam relações com as demandas políticas dos afro-brasileiros, assim como aos idosos e portadores de deficiência física. Em diversas situações públicas o senador empunhou uma lança, em alusão aos lanceiros negros. Recentemente, o senador indicou a Família Silva - comunidade que passa por processo de reconhecimento enquanto "quilombo urbano" na cidade de Porto Alegre - para o recebimento de tal troféu, que é conferido pelo Senado Federal.
}

Horizontes Antropológicos, Porto Alegre, ano 17, n. 36, p. 171-195, jul./dez. 2011 


\section{A inscriç̃o material dos referentes culturais}

Durante o INRC, o episódio e o lugar do Massacre de Porongos se impuseram como referentes concretos da trajetória do negro no Rio Grande do Sul. Através deles, os representantes dos diferentes grupos e movimentos se localizavam no tempo e no espaço, referindo-se a um passado trágico - a dizimação do corpo de lanceiros negros e a derrota dos republicanos frente aos imperiais ocorrendo num momento e local comum. Ao mesmo tempo, como constatamos ao longo deste artigo, os grupos e atores pesquisados procuraram inscrever incessantemente esse passado no presente, seja através de celebrações e eleição de "lugares de memória", seja através da produção de textos e imagens evocando o papel do negro no Rio Grande do Sul através da figura emblemática do lanceiro negro durante a Revolução Farroupilha.

Assim, ainda que a discussão histórica tenha servido de pano de fundo para as discussões realizadas junto aos locais, atores e grupos visitados, a memória do Massacre de Porongos parece estar imaginariamente acoplada à figura do lanceiro negro, pois é partir dela que os grupos e atores pesquisados ancoravam suas relações identitárias. Além das situações já analisadas que reforçam essa ideia, podemos citar a presença de "manequins" de lanceiros negros (que estariam utilizando indumentárias de guerra típicas da época) nas instalações do Instituto Gaúcho de Tradição e Folclore, em Porto Alegre. Outro exemplo diz respeito a produções musicais e literárias: o tema dos lanceiros negros tem aparecido frequentemente nos festivais musicais do estado desde a década de $1980^{16}$ e em obras literárias de escritores como Oliveira Ferreira Silveira desde a década de $1970 .{ }^{17}$

Nesse sentido, o reconhecimento do papel do negro na construção do "homem rio-grandense" não se encerra nas hesitações e polêmicas

${ }^{16}$ Como exemplo, podemos citar Os lanceiros negros, composta por Newton Bastos e Dilan Camargo; $O$ negro de trinta e cinco, composta por José Rufino Aguiar e Clóvis de Souza; e o Negro do charque, de José Hilário Retamozo.

17 O poemeto "Décima do negro peão", escrito por Oliveira Silveira em 1970, é publicado em 1974; o livro Pêlo escuro, do mesmo autor, data de 1977 e contém os poemas "Carga de lança" e "Ao negro guerreiro" (Silveira, 1974, 1977). Cabe notar também que Oliveira Silveira é um dos idealizadores do 20 de novembro enquanto data emblemática da comunidade negra, por fazer alusão à morte de Zumbi dos Palmares. A data foi incorporada como data oficial ainda na década de 1970 pelo Movimento Negro Unificado (MNU). Essa data incorpora-se no circuito de atividades que envolve, anualmente, no mês de novembro, a "Semana da Consciência Negra". 
historiográficas. No caso do INRC Porongos, visto que não foi possível atestar todas as condições do massacre ou suas consequências no processo de libertação dos negros ao final da Revolução Farroupilha, coube ao trabalho de definição dos locais de celebração e de memória e à recuperação de iconografias e narrativas relacionadas ao ocorrido a função de articular os elementos culturais constitutivos desse processo de reconhecimento.

Ora, considerando que essa articulação de elementos culturais se desdobra em diversas práticas sociais - de ações mediáticas e espetaculares (produção de uma minissérie por uma grade empresa de comunicação), passando por decisões políticas (compra de uma parte do Cerro de Porongos para a construção de um memorial), até atividades de ordem local ou pontual (palestras, cavalgadas, publicações informais) -, uma interrogação sobre o papel político do INRC Porongos enquanto agente de consolidação desses elementos culturais é necessária. Se cabe ao inventário o registro de práticas, saberes e manifestações culturais para, se for o caso, inscrevê-los nos Livros de Registro do Iphan, sob quais condições a atribuição de "valor cultural" a tais práticas, saberes e manifestações implica disputas políticas e reformulações histórico-identitárias?

Antes de responder a essa questão, vale ressaltar que a "politização da cultura" própria ao INRC Porongos não é um caso à parte - e nem tampouco a figuração do lanceiro negro enquanto fundamento imaginário de lutas simbólicas em torno das representações legítimas do negro e do gaúcho no Rio Grande do Sul. O que é exemplar no caso do INRC é a maneira pela qual essa politização se efetua na prática. A esse respeito, cabe ressaltar três pontos:

1) Em primeiro lugar, ainda que o INRC se caracterize pelo trabalho de colecionamento de bens culturais ditos "imateriais" ou "intangíveis", ${ }^{18}$ é preciso reconhecer que o inventariamento de determinadas localidades, celebrações e práticas sociais contribui para articular a "teia de objetos" (Gonçalves, 2002, 2007) que serve de referência para a constituição de formas de subjetividade e de reconhecimento individuais e coletivas.

18 Como já comentado anteriormente, nós rejeitamos a distinção entre bens materiais e imateriais enquanto categorias de entendimento/classificatórias universais. Nós aceitamos porém a ideia de que tais noções podem ser úteis quando se trata de compreender como os grupos sociais pensam e organizam o seu mundo a partir delas (cf. Geertz, 1989; Sahlins, 2003). 
2) Nesse sentido, o processo de inventariamento vem "materializar" referentes culturais como formas de expressão, narrativas, gestos e saberes. Assim, apesar de se apresentar no registro de "patrimônio imaterial", o INRC Porongos possibilitou a fabricação de um "corpo" (de textos e imagens) e a delimitação de "lugares" (de memória) a partir dos quais as formas de expressão, narrativas, gestos e saberes vêm se inscrever.

3) Finalmente, se considerarmos o peso de prova que os bens e referentes culturais adquirem através do processo de colecionamento e patrimonialização, o INRC Porongos se impõe como um fabricante das provas que irão alimentar os debates e disputas políticas em torno das representações legítimas, no caso as do negro e as do gaúcho no estado do Rio Grande do Sul.

Efetivamente, perguntas sobre a "verdade" do Massacre de Porongos e sobre o "verdadeiro" fim dos lanceiros negros acompanharam todo o processo de inventário. As pessoas encontradas queriam saber a exata localização do acampamento e se interessavam pelas possíveis ossadas que ali poderiam estar depositadas. Finalmente, a pedido da prefeitura de Pinheiro Machado, um trabalho de escavação arqueológica foi realizado no interior dos três hectares do Cerro de Porongos pertencentes ao poder público. O resultado - que já conhecíamos de antemão em razão da qualidade do solo própria à região - foi desanimador. Nenhum osso, nenhuma arma. Apenas restos de cerâmica indígena datando de períodos anteriores à Revolução Farroupilha.

As iniciativas em torno da construção do Memorial dos Lanceiros Negros, no Cerro de Porongos, também comportavam uma preocupação com a elaboração de provas materiais sobre o massacre e, por extensão, sobre o papel do negro na história do Rio Grande do Sul. Em uma entrevista de Luiz Mendes, secretário de Comunicação da ONG Centro Cultural Cândido Velho e integrante da Comissão ao Memorial aos Lanceiros Negros ${ }^{19}$ ficou clara a sua preocupação com a construção de um monumento à memória dos negros que "lutaram pelas suas liberdades" e que "eram temidos por isso". Para ele,

19 A formação de uma Comissão ao Memorial dos Lanceiros Negros, em 2003, articulou diversos atores interessados em discutir o memorial - seu formato, finalidade, formas de elaboração, etc. Em 2005, foi lançado o edital de concurso para a construção do memorial no Cerro de Porongos, assim como de um monumento, no Parque Farroupilha, na cidade de Porto Alegre.

Horizontes Antropológicos, Porto Alegre, ano 17, n. 36, p. 171-195, jul./dez. 2011 
a simples identificação do Cerro de Porongos como local do massacre ou a documentação de narrativas relacionadas ao evento não poderiam bastar enquanto referências simbólicas para os negros de Pinheiro Machado e do Rio Grande do Sul: caberia ao próprio memorial, através de seus elementos estéticos e arquitetônicos, a função de incorporar a força do negro enquanto sujeito da história. Nesse sentido, o INRC Porongos aparecia como fonte documental e apoio institucional para a cristalização de elementos culturais, históricos e políticos considerados essenciais pelos atores e grupos envolvidos.

Ainda no que diz respeito ao memorial, alguns grupos criticavam a iniciativa através de argumentos de matrizes políticas, culturais e religiosas diversas. O artista plástico Ney Ortiz (diretor cultural do Centro Raízes d'África, de Porto Alegre), por exemplo, argumentou certa vez que a construção de um memorial, seja qual for o seu formato, estaria "tampando" os heróis que lá morreram. Ele justifica sua posição através de uma analogia com casas de terreiro de santos (batuque, no caso do Rio Grande do Sul), dizendo que nelas não deve ser construído um segundo andar a fim de não "pisar" nos orixás. Nesse sentido, as divindades africanas iorubás, orixás e lanceiros negros são colocados, metaforicamente, em um mesmo patamar de sacralidade. Outro exemplo de ressalva relativa ao memorial partiu do próprio Iphan, cujos técnicos insistiam na proteção do patrimônio natural. Em outras palavras, seria fundamental refletir com cuidado no tipo de construção pretendida a fim de evitar possíveis impactos ambientais.

Seja como for, tendo em vista os argumentos favoráveis e contrários com relação a tal construção, fica clara aqui a expectativa em torno da "materialização" do massacre. Os atores e grupos pesquisados aspiravam, cada qual à sua maneira, a um estatuto de "verdade" sobre ocorrido através de sua inscrição patrimonial, ampliando seu sentido e cristalizando um evento histórico importante nas lutas por definições identitárias no Rio Grande do Sul.

O que é fundamental aqui - e essa é a nossa tese - é que os usos e abusos das referências culturais próprias às disputas em torno das representações legítimas do negro e do gaúcho no Rio Grande do Sul se alimentam através dessa inscrição material favorecida pelo processo de inventariamento. Nós concordamos, portanto, com o caráter de "enquadramento mítico" que, segundo José Reginaldo Santos Gonçalves (2002), seria característico dos objetos que integram as coleções e os patrimônios nacionais e regionais. Mas gostaríamos de reforçar a ideia de que mesmo os referentes culturais pensados como 
"intangíveis" ou "imateriais" por determinados grupos e atores podem servir como "sinais diacríticos das categorias e grupos sociais que venham a representar" (Gonçalves, 2002, p. 23).

Dito de outra maneira, uma vez legitimados através da ação institucional do Iphan, os elementos representacionais relativos ao Massacre de Porongos e à figura do lanceiro negro ganham um peso de verdade que pode ser comparado ao da "pedra e cal" (Fonseca, 2003). Daí a necessidade de apresentarmos, durante e após o INRC, resultados parciais de nossa pesquisa junto a determinados grupos. Vídeos de entrevistas e fotografias das localidades e dos elementos pictóricos recolhidos durante o inventariamento foram sistematicamente apresentados a fim dar conta daquilo que podemos chamar de "anseio de materialização dos referentes culturais" documentados ao longo do processo.

No final das contas, o reconhecimento do papel do lanceiros negros na história do Rio Grande do Sul se articula diretamente com a construção e delimitação dos referentes culturais documentados pelo INRC Porongos, sejam eles considerados "materiais" ou "imateriais". Aliás, tal distinção, ainda que discutível de um ponto de vista epistemológico onde os seres humanos se relacionam com o mundo a partir de esquemas e sistemas simbólicos (Geertz, 1989; Gonçalves, 2005; Sahlins, 2003) continua sendo operacional do ponto de vista dos grupos e atores estudados. Para estes, o que é bom para pensar o Massacre de Porongos e os lanceiros negros é aquilo que faz figura de prova, seja ela apresentada através de textos e de imagens ou de lugares e edificações. Em outras palavras, se o INRC Porongos agiu politicamente na reconstituição dos elementos culturais que servem de apoio à formulação e à delimitação de identidades locais e regionais, isso se deve em grande parte à sua ação documental - ou, como gostamos de dizer, ao trabalho de materialização do patrimônio imaterial.

\section{Referências}

ANICO, M. A pós-modernização da cultura: património e museus na contemporaneidade. Horizontes Antropológicos, ano 11, n. 23, p. 71-86, 2005.

BACZKO, B. Imaginação social. In: ENCICLOPÉDIA EINAUDI. Lisboa: Imprensa Nacional/Casa da Moeda, 1985. v. 5, p. 346-396. 
BAKOS, M. M. A escravidão negra e os farrapos. In: DACANAL, J. H. (Org.). A Revolução Farroupilha: história e interpretação. Porto Alegre: Mercado Aberto, 1985. p. 124-138.

BARCELLOS, D. M. Família e ascensão social de negros em Porto Alegre. Tese (Doutorado em Antropologia Social)-Museu Nacional/Universidade Federal do Rio de Janeiro, Rio de Janeiro, 1996.

BRUM, C. K. Esta terra tem dono: disputas e representações sobre passado missioneiro no Rio Grande do Sul: a figura de Sepé Tiarajú. 2004. Manuscrito.

CARRION, R. Os lanceiros negros na Revolução Farroupilha. Porto Alegre: Assembleia Legislativa do Rio Grande do Sul, 2008. Disponível em: <http:// www.raulcarrion.com.br/lanceiros.pdf $>$. Acesso em: 20 fev. 2011.

CARVALHO, D. V.; OLIVEIRA, V. P. de. Os lanceiros Francisco Cabinda, João Aleijado, Preto Antonio e outros personagens negros na Guerra dos Farrapos. In: SILVA, G. F. da; SANTOS, J. A. dos; CARNEIRO, L. C. da C. (Org.). RS negro: cartografias sobre a produção do conhecimento. Porto Alegre: EDIPUCRS, 2008. v. 1, p. 63-82.

CASSIRER, E. Ensaio sobre o homem: introdução a uma filosofia da cultura humana. São Paulo: Martins Fontes, 1994.

CHEUICHE, A. A Guerra dos Farrapos. Porto Alegre: Mercado Aberto, 1985. CHOAY, F. A alegoria do patrimônio. São Paulo: Unesp, 2001.

DELGADO, A. F. Goiás: a invenção da cidade "Patrimônio da Humanidade". Horizontes Antropológicos, ano 11, n. 23, p. 113-143, 2005.

DURAND, G. L’imagination symbolique. 5. ed. Paris: PUF, 2003.

FERREIRA, M. L. M. Batalhas no campo da memória e dos museus: disputas sobre o sentido do passado, lutas pelo reconhecimento. In: CHAGAS, M. de S.; BEZERRA, R. Z.; BENCHETRIT, S. F. A democratização da memória: a função social dos museus Ibero-Americanos. Rio de Janeiro: Museu Histórico Nacional, 2008. p. 53-70. 
FLORES, M. Modelo político dos farrapos. 3. ed. Porto Alegre: Mercado Aberto, 1985.

FONSECA, M. C. L. Para além da pedra e cal: por uma concepção ampla de patrimônio cultural. In: ABREU, R.; CHAGAS, M. (Org.). Memória e patrimônio: ensaios contemporâneos. Rio de Janeiro: DP\&A, 2003. p. 56-76.

GEERTZ, C. A interpretação das culturas. Rio de Janeiro: LTC, 1989.

GONÇALVES, J. R. S. A retórica da perda: os discursos do patrimônio cultural no Brasil. 2. ed. Rio de Janeiro: Universidade Federal do Rio de Janeiro, 2002.

GONÇALVES, J. R. S. Ressonância, materialidade e subjetividade: as culturas como patrimônios. Horizontes Antropológicos, ano 11, n. 23, p. 15-36, jan./jun. 2005.

GONÇALVES, J. R. S. Antropologia dos objetos: coleções, museus e patrimônios. Rio de Janeiro: Garamond; MinC/Iphan/Demu, 2007.

LEITMAN, S. Negros farrapos: hipocrisia racial no sul do Brasil no século XIX. In: DACANAL, J. H. (Org.). A Revolução Farroupilha: história e interpretação. Porto Alegre, Mercado Aberto, 1997. p. 30-60.

MACIEL, M. E. Le gaúcho Brésilien: identité culturelle dans le sud du Brésil. Tese (Doutorado em Antropologia Social)-Université de Paris V, René Decartes, Sorbonne, Paris, 1994a.

MACIEL, M. E. Considerações sobre gaúchos e colonos. In: BAQUERO, M. et al. Diversidade étnica e identidade gaúcha. Santa Cruz do Sul: Editora da UNISC, 1994b. p. 31-42.

MACIEL, M. E. Tradição e tradicionalismo no Rio Grande do Sul. Humanas: Revista do Instituto de Filosofia e Ciências Humanas, v. 22, n. 1/2, p. 127-144, 1999.

MEIRA, A. G. Políticas públicas e gestão do patrimônio histórico. História em Revista, v. 10, dez. 2004. Disponível em: <http://www.ufpel.edu.br/ich/ndh/ downloads/historia_em_revista_10_ana_meira.pdf >. Acesso em: 20 fev. 2011. 
NORA, P. Entre memória e história: a problemática dos lugares. Projeto História, n. 10, p. 7-28, dez. 1993.

OLIVEIRA, E. D.; GRAEFF, L. Em defesa da Villa Mimosa: uma luta em torno do patrimônio cultural e ambiental de Canoas/RS. In: BERND, Z.; SANTOS, N. M. W.; ADOLFO, G. Bens culturais: temas contemporâneos. Canoas: Salles, 2011. No prelo. (Série Memória e Patrimônio Unilasalle, n. 3 ).

OLIVEN, R. G. O maior movimento de cultura popular do mundo ocidental: o tradicionalismo gaúcho. Cadernos de Antropologia, v. 1, p. 1-46, 1990.

OLIVEN, R. G. A parte e o todo. Rio de Janeiro: Vozes, 1992.

PELEGRINI, S. C. A. A gestão do patrimônio imaterial brasileiro na contemporaneidade. História, v. 2, n. 27, p. 145-173, 2008.

PEIXOTO, P. "Porto Feliz": património em segurança. Horizontes Antropológicos, ano 11, n. 23, p. 145-161, 2005.

PESAVENTO, S. J. Os farrapos. Nossa História, v. 2, n. 15, p. 54-58, 2005.

POULOT, D. Um ecossistema do patrimônio. IN: RODRIGUES, C. S. de C. et al. Um olhar contemporâneo sobre a preservação do patrimônio cultural material. Rio de Janeiro: Museu Histórico Nacional, 2008. p. 26-43.

RIETH, F. et al. Inventário nacional de referências culturais: produção de doces tradicionais pelotenses (relatório final). Pelotas: Ed. Universitária/ UFPel, 2008. v. 1.

SAGI, L. Gestão pública da hospitalidade urbana: estudo de caso do Parque da Água Branca na cidade de São Paulo. Revista Brasileira de Pesquisa em Turismo, v. 2, n. 3, p. 90-105, 2008.

SALAINI, C. J. O negro no campo artístico: uma possibilidade analítica de espaços de solidariedade étnica em Porto Alegre/RS. In: SILVA, G. F. da; SANTOS, J. A. dos; CARNEIRO, L. C. da C. (Org.). RS negro: cartografias sobre a produção do conhecimento. Porto Alegre: EDIPUCRS, 2008. v. 1, p. 148-162. 
SALAINI, C. J.; COMIN, A. P. Memória, mídia e imaginário social: o caso Porongos. Ilha: Revista de Antropologia, v. 10, p. 155-173, 2010.

SAHLINS, M. Cultura e razão prática. Rio de Janeiro: Jorge Zahar, 2003.

SILVA, A. Imaginários urbanos. São Paulo: Perspectiva, 2001.

SILVEIRA, O. Décima do negro peão. Porto Alegre, 1974.

SILVEIRA, O. Pêlo escuro: poemas afro-gaúchos. Porto Alegre, 1977.

UNESCO. Convenção para a proteção do patrimônio mundial, cultural $e$ natural. 1972. Disponível em: <http://www.dominiopublico.gov.br/ pesquisa/DetalheObraForm.do?select_action $=\&$ co_obra $=14812>$. Acesso em: 20 fev. 2011.

Recebido em: 27/02/2011

Aprovado em: 22/08/2011 